\title{
The Preparation of Magnetic Iron Oxide Nanoparticles in Microreactors
}

\author{
Matthew Simmons ${ }^{1}$, Charlotte Wiles ${ }^{2}$, Vincent Rocher ${ }^{2}$, M. Grazia Francesconi ${ }^{1 *}$ and Paul Watts ${ }^{1,3}$ * \\ ${ }^{1}$ Department of Chemistry, The University of Hull, Cottingham Road, Kingston upon Hull HU6 7RX, UK \\ ${ }^{2}$ Chemtrix BV, Burgemeester Lemmensstraat 358, $6163 \mathrm{JT}$, Geleen, The Netherlands \\ ${ }^{3}$ InnoVenton: NMMU Institute for Chemical Technology, Nelson Mandela Metropolitan University, PO Box 77000,
}

Port Elizabeth 6031, South Africa

\begin{abstract}
The preparation of magnetic iron oxide nanoparticles within microreactors is reported. The proportion of $\gamma-\mathrm{Fe}_{2} \mathrm{O}_{3}$ and $\mathrm{Fe}_{3} \mathrm{O}_{4}$ in the sample was determined, an important parameter for reproducibility in applications.
\end{abstract}

Keywords: Magnetic nanoparticles, Microreactors, Laminar flow, Nanoparticle synthesis, nanoparticle analysis

\section{Introduction}

A microreactor is used for the the preparation of magnetic iron oxide nanoparticles, containing a mixture of $\mathrm{Fe}_{3} \mathrm{O}_{4}$ and $\gamma-\mathrm{Fe}_{2} \mathrm{O}_{3}$, a critical step towards the development of methods suitable for large scale synthesis. In addition, the proportion of $\gamma-\mathrm{Fe}_{2} \mathrm{O}_{3}$ and $\mathrm{Fe}_{3} \mathrm{O}_{4}$ in the samples was determined, an important parameter for reproducibility in applications. Although, seminal work by Frenz et al. [1], Abou-Hassan et al. [2], Kumar et al. [3], and Chin et al. [4] have shown the advantages of using continuous flow technology to prepare iron oxide nanoparticles using either tubular reactors or spinning disc processing, the homemade reactors were subjected to ad hoc modifications meaning that it would be very difficult to implement the technology on an industrial scale. However, the last few years have seen substantial developments in the commercial accessibility of micro reactor technology, meaning that industrial implementation is much closer to reality [5]. With this in mind, we have used such a system to prepare iron oxide nanoparticles. In addition, we have combined several analytical techniques in order to characterize the product and determine accurately the percentage of $\gamma-\mathrm{Fe}_{2} \mathrm{O}_{3}$ and $\mathrm{Fe}_{3} \mathrm{O}_{4}$ present in the samples which has not previously been performed upon nanoparticles produced using flow techniques.

Microreactors are now a common tool for the study and optimization of a wide variety of synthetic organic and inorganic reactions $[6,7]$. When compared to traditional bulk reactions, the use of microreactors leads to many practical advantages, such as a higher degree of control of the reaction conditions and increased reproducibility [8]. In the field of nanotechnology, greater control of reaction conditions has led to smaller particle sizes and lower degrees of polydispersity [9]. Microfluidic systems have been shown to be able to produce a variety of metal ( $\mathrm{Au}$ [10], $\mathrm{Ag}$ [11], $\mathrm{Pd}$ [12], and $\mathrm{Cu}$ [13]) and metal oxide nanoparticles $\left(\mathrm{TiO}_{2}[14]\right.$ and $\left.\mathrm{SiO}_{2}[15,16]\right)$; as well as synthetically challenging structures, including core shell nanoparticles and quantum dots [17].

Iron oxide nanoparticles (IONs) are particularly sought after for their numerous technological applications, in particular for their use as MRI contrast agents and hyperthermia cancer treatments [18-20]. For reliable and reproducible applications of IONs, exquisite control of particle size and phase composition is required. Nanoparticle size and polydispersity are important factors for biomedical applications as these control the rate at which the particles are excreted from the body, while also being a controlling factor for the superparamagnetic properties of the nanoparticles [21]. The composition of samples of IONs is also important as the chemical formula of the iron oxides is

\footnotetext{
* Author for correspondence: M.G.Francesconi@hull.ac.uk and
}

P.Watts@hull.ac.uk closely related to their magnetic properties. Several iron oxides are known; however, only $\gamma-\mathrm{Fe}_{2} \mathrm{O}_{3}$ and $\mathrm{Fe}_{3} \mathrm{O}_{4}$ are currently of interest for biomedical applications due to the magnetic properties of these nanoparticles. The two structures of $\gamma-\mathrm{Fe}_{2} \mathrm{O}_{3}$ and $\mathrm{Fe}_{3} \mathrm{O}_{4}$ are very similar, both based upon a FCC lattice of $\mathrm{O}^{2-}$ anions. $\mathrm{In} \mathrm{Fe}_{3} \mathrm{O}_{4}, \mathrm{Fe}^{2+}$ cations are located in the octahedral holes, and $\mathrm{Fe}^{3+}$ cations are in both the octahedral and tetrahedral holes. As both structures are based on an FCC lattice, $\mathrm{Fe}_{3} \mathrm{O}_{4}$ can be interconverted into $\gamma-\mathrm{Fe}_{2} \mathrm{O}_{3}$ via oxidation and formation of cation vacancies, the distribution of these vacancies having a large effect upon the unit cell [22-24]. The nanoparticles of both $\gamma-\mathrm{Fe}_{2} \mathrm{O}_{3}$ and $\mathrm{Fe}_{3} \mathrm{O}_{4}$ show similar magnetic properties but, as expected, not identical. In fact, the magnetic saturation of $\gamma-\mathrm{Fe}_{2} \mathrm{O}_{3}$ is approximately $20 \%$ lower than that of $\mathrm{Fe}_{3} \mathrm{O}_{4}$ [25]. Differentiation between the two spinel phases is difficult, but can be accomplished through peak deconvolution of peaks in a powder X-ray diffraction pattern, or through a combination of X-ray absorption spectroscopy (XAS) and X-ray magnetic circular dichroism (XMCD) measurements [26, 27].

Continuous flow microreactors are often seen to suffer from particle adsorption upon the surface of the reactor walls, which ultimately leads to clogging of the channels. Within the field of particle synthesis, this problem has been overcome using droplet coalescense and co-axial flow techniques. Droplet coalescense has been used in seminal work on the synthesis of iron oxide nanoparticles in microreactors by Frenz et al. [1] and Kumar et al. [3]. Kumar et.al. have also noted in the presence of both spinel phases of $\mathrm{Fe}_{3} \mathrm{O}_{4}$ and $\gamma-\mathrm{Fe}_{2} \mathrm{O}_{3}$ in the EDX analysis of their product. Droplet coalescence involves forming the particles in aqueous droplets within an oil-based carrier phase. Consequenty, it is difficult to separate the nanoparticles from the aqueous and carrier phases due to the surfactants used to control droplet size. Furthermore, the synthesis of iron oxide nanoparticles was carried out in purpose-made continuous flow reactors. Consequently, this approach is only suitable for smallscale research applications and could not be implemented reproducibly on a large scale, mainly for two reasons; firstly the length of tubing required would cause pressure drop problems and secondly the carrier phase used is often an expensive fluorocarbon oil.

Our aim was to develop an easy-to-scale-up and reproducible method for the production of IONs in microreactors. We carried out the reaction in a commercially available glass microreactor using continuous flow of both reagent streams in order to avoid the use of two phases. We successfully ran the reaction for 40 hours without blockage, this was achieved by tailoring the flow rate and delaying the precipitation until the serpentine channel (after the T mixer); facilitating removal of the nanoparticles simply by the flow of the mixture. The reactor 


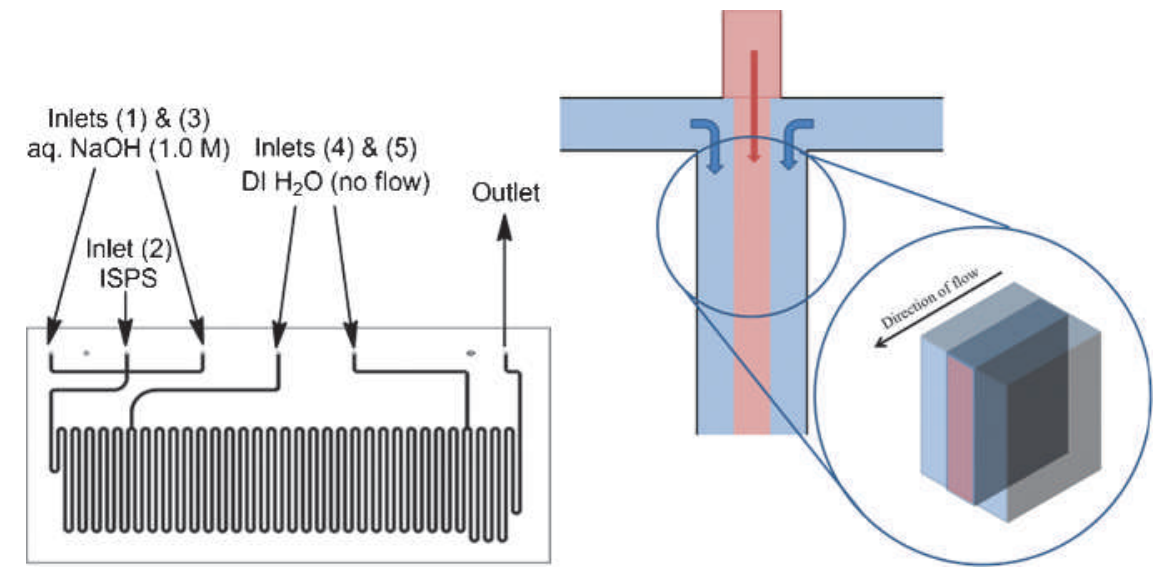

Figure 1. Reactor design 3025 obtained from the Labtrix ${ }^{\circledR}$ Start Set. Iron salts precursor solution (ISPS) is pumped into inlet 2, while NaOH solution is simultaneously pumped into inlets 1 and 3 at a total flow rate of $3000 \mu l$ hour $^{-1}$. The inset shows how the fluids mix and react at the T-mixer, highlighting how the iron salts precursor solution (red) is focused between two flows of excess sodium hydroxide (blue).

comprised of one etched layer and one cover plate, which upon bonding afforded isotropic channels of a depth of $60 \mu \mathrm{m}$ and width of $300 \mu \mathrm{m}$ (volume $10 \mu \mathrm{l})$. The reactor design allowed three single reagent streams to come together. The reaction of divalent and trivalent iron salts with a concentrated base is a common route to forming iron oxide nanoparticles [28-30]. Therefore, we strategically introduced the iron salt precursor solution (divalent and trivalent iron chloride salts dissolved in $1.10 \mathrm{~mol} \mathrm{dm}^{-3}$ hydrochloric acid) between two continuous streams of sodium hydroxide solution $\left(1.0 \mathrm{~mol} \mathrm{dm}^{-3}\right)$ (Figure 1). Under the laminar flow conditions obtained within such micro reactors, where mixing occurs exclusively by molecular diffusion, it needs to be emphasized that the speed of mixing is directly related to the flow rate within the channel. Consequently, the speed of precipitation is highly controlled. Furthermore, under these flow conditions ( $3000 \mu 1$ hour $^{-1}$ total, $1000 \mu 1$ hour $^{-1}$ each), the particles flow freely from the reactor avoiding blockage; no backpressure regulator (BPR) was employed. We have routinely used the reactor for 40 consecutive runs, equivalent to 40 hours total reaction time without adsorption of nanoparticles on the microreactor walls causing any significant problems. After 40 runs of the microreactor, percentage yields of up to $97 \%$ were obtained, with any loss of product attributed to particle adsorption or the production of non-magnetic biproducts (e.g. $\gamma$-FeOOH) which are lost upon particle isolation. Each reaction produced a mixture of magnetic particles which were separated from any non-magnetic impurities using magnetic decantation.
TEM showed that the particles were roughly spherical in shape (Figure 2), and the particle diameters were measured using ImageJ software and were found to have an average diameter of $3.6 \pm 1.0 \mathrm{~nm}$; consistent with the size calculated using the Scherrer formula (2.89 $\mathrm{nm}$ in diameter) [30, 31]. While the size distribution of the nanoparticles may appear to be unfavorably high $(\approx 30 \%)$, it must be considered that the targeted application of these nanoparticles is for use in MRI treatments. MRI contrast agents utilizing IONs currently available upon the market typically have sizes ranging between 30 and $40 \mathrm{~nm}$ [21]. The nanoparticle size is comparable with that observed by Frenz et.al. and Abou-Hassan et.al. who prepared IONs using ad hoc micro reactors of $4 \mathrm{~nm}$ and $7 \mathrm{~nm}$, respectively $[1,2]$. From the particle size distributions and standard deviation, it can be seen that the commercial micro reactor used in this work produced nanoparticles with comparible polydispersity. No extensive attempts to determine the nature of the IONs prepared in microreactors has been made to date. In the research presented by previous groups, a combination of EDX and magnetic measurements was used, whereby the authors concluded that only nanoparticles of $\gamma-\mathrm{Fe}_{2} \mathrm{O}_{3}$ were prepared $[1,2]$. We wanted to investigate whether our products consisted of either $\gamma-\mathrm{Fe}_{2} \mathrm{O}_{3}$ or $\mathrm{Fe}_{3} \mathrm{O}_{4}$ only, or a mixture of both as was also observed by Kumar et al. [3].

We used powder X-ray diffraction (PXRD) to determine the composition of our sample both qualitatively and quantitatively. The PXRD patterns (Figure 3) were not unambiguous, in that the diffraction peaks could be attributed to $\mathrm{Fe}_{3} \mathrm{O}_{4}$ and $\gamma-\mathrm{Fe}_{2} \mathrm{O}_{3}$.
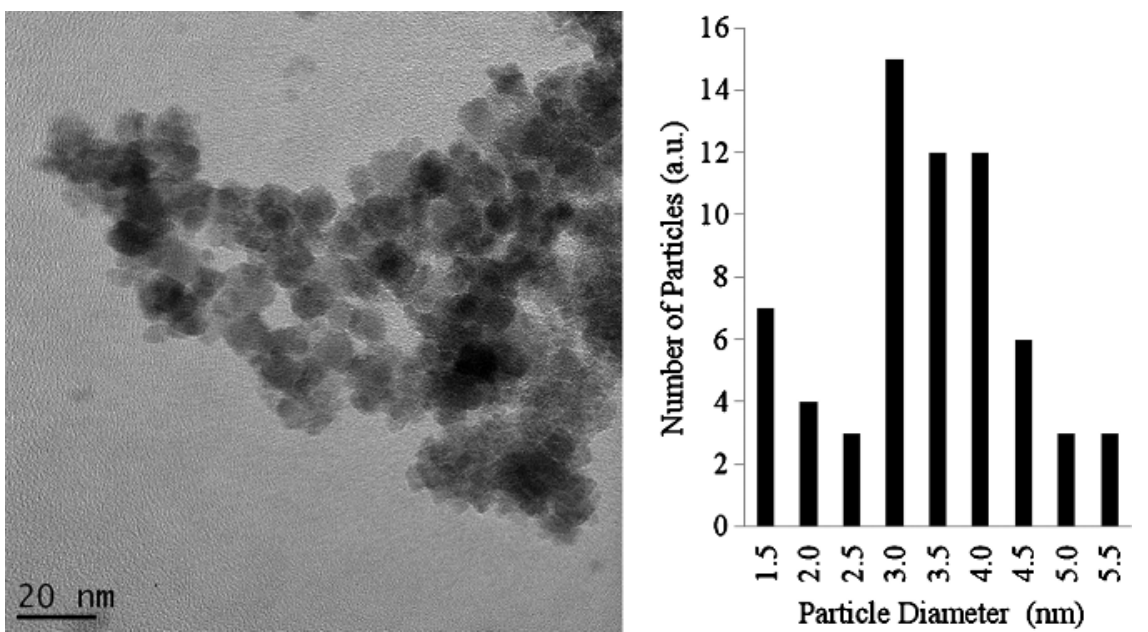

Figure 2. TEM images of the microreactor sample accompanied by the relative size distribution of the nanoparticles produced at a total flow rate of $3000 \mu \mathrm{l}$ hour $^{-1}$. 


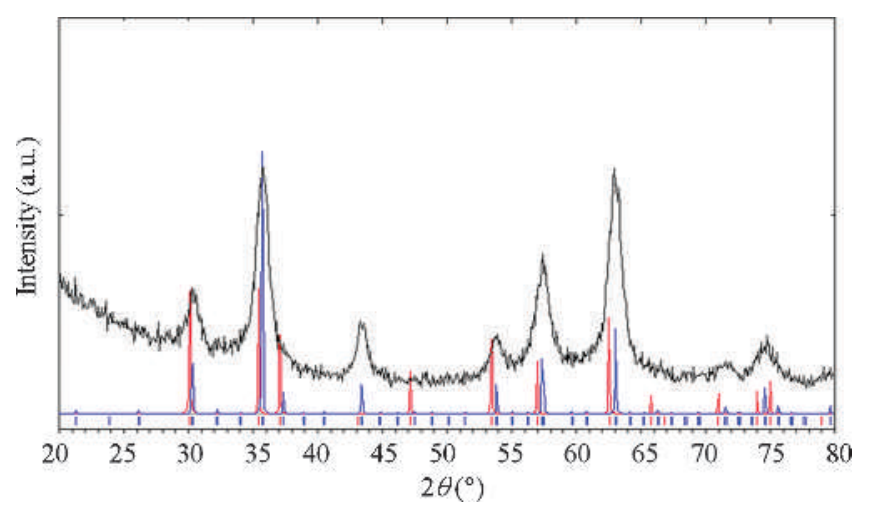

Figure 3. PXRD pattern of the IONs synthesised in the commercial microreactor (black) compared with the PXRD patterns of $\mathrm{Fe}_{3} \mathrm{O}_{4}$ (red) and $\gamma-\mathrm{Fe}_{2} \mathrm{O}_{3}$ (blue) from references 25 and 20, respectively.

The structures of the $\gamma-\mathrm{Fe}_{2} \mathrm{O}_{3}$ and $\mathrm{Fe}_{3} \mathrm{O}_{4}$ are very similar as both are based on an FCC lattice with a larger size of the unit cell for $\mathrm{Fe}_{3} \mathrm{O}_{4}$ than $\gamma-\mathrm{Fe}_{2} \mathrm{O}_{3}\left(a=8.3941(7)\right.$ for $\mathrm{Fe}_{3} \mathrm{O}_{4} ; a=b=$ $8.3396(4), c=8.3220(7)$ for $\left.\gamma-\mathrm{Fe}_{2} \mathrm{O}_{3}\right)[22,23,32]$. However, the broadening of the diffraction peaks caused by the nanosize of the particles does not allow the small difference in $2 \theta$ angles to be detected. Also, the ordering of the cation vacancies in $\gamma-\mathrm{Fe}_{2} \mathrm{O}_{3}$ lead to a tetragonal unit cell, with additional diffraction peaks compared to $\mathrm{Fe}_{3} \mathrm{O}_{4}$; however, these reflections are size dependent and disappear for mean particle size $<20 \mathrm{~nm}$ [23].

$\mathrm{Fe}_{3} \mathrm{O}_{4}$ is frequently non-stoichiometric $\left(\mathrm{Fe}_{3-\delta} \mathrm{O}_{4}\right)$ and has been found to oxidize easily into a series of intermediates with varying content of $\mathrm{Fe}^{2+}$ ions (magnetite-maghemite solid solution) [33]. Partial oxidization of $\mathrm{Fe}_{3} \mathrm{O}_{4}$ has been suggested by other groups for nanoparticles with diameters smaller than $40 \mathrm{~nm}$ and may be unavoidable [30]. In fact, it was reported that in nanoparticles with size approximatly below $10 \mathrm{~nm}$, a mixture of $\mathrm{Fe}_{3} \mathrm{O}_{4}$ and $\gamma-\mathrm{Fe}_{2} \mathrm{O}_{3}$ is always present.

We determined the fraction of $\gamma-\mathrm{Fe}_{2} \mathrm{O}_{3}$ and $\mathrm{Fe}_{3} \mathrm{O}_{4}$ in our samples using PXRD data and a peak deconvolution method reported by Kim et al. [27]. A calibration graph of the integrated intensity of the diffraction peaks versus the weight percentage of $\gamma-\mathrm{Fe}_{2} \mathrm{O}_{3}$ was drawn from experimental data. The integrated intensity of the (511) reflection was then compared to a calibration graph. The weight percentage of $\gamma-\mathrm{Fe}_{2} \mathrm{O}_{3}$ present within the IONs was determined to be $71.8 \%$, and therefore, the weight percentage of $\mathrm{Fe}_{3} \mathrm{O}_{4}$ was determined to be $28.2 \%$.

A vibrating sample magnetometer (VSM) was used to study the magnetic properties of the IONs produced within the glass microreactor. The recorded magnetization curve (Figure 4) shows that the IONs show very low coercivity and remanence values. This absence of a hysteresis loop is characteristic of superparamagnetic behavior and confirms the nanometric size of the particles. At low fields, the magnetization displays a fast increase, which gradually slows down. However, the plateau that should be then observed due to the magnetic saturation of the sample being reached is replaced by a slower increase. Considering that in this case this phenomenon cannot be linked to a wide polydispersity in the size of the particles, this suggests the formation of aggregates, a phenomenon against which the freshly prepared particles are not protected. Thus, only the magnetization curve, up to about $3000 \mathrm{Oe}$, can be used to estimate the size of the nanoparticles [2].

Control of the weight percentage of $\gamma-\mathrm{Fe}_{2} \mathrm{O}_{3}$ and $\mathrm{Fe}_{3} \mathrm{O}_{4}$ within iron oxide nanoparticles is therefore of great importance as this would prove the simplest way to control the magnetic properties of the particles; to the best of the authors knowledge, this is yet to be achieved. Using the system we have developed herein, control of the weight percentage of both $\gamma-\mathrm{Fe}_{2} \mathrm{O}_{3}$ and $\mathrm{Fe}_{3} \mathrm{O}_{4}$ should be achievable through the addition of suitable

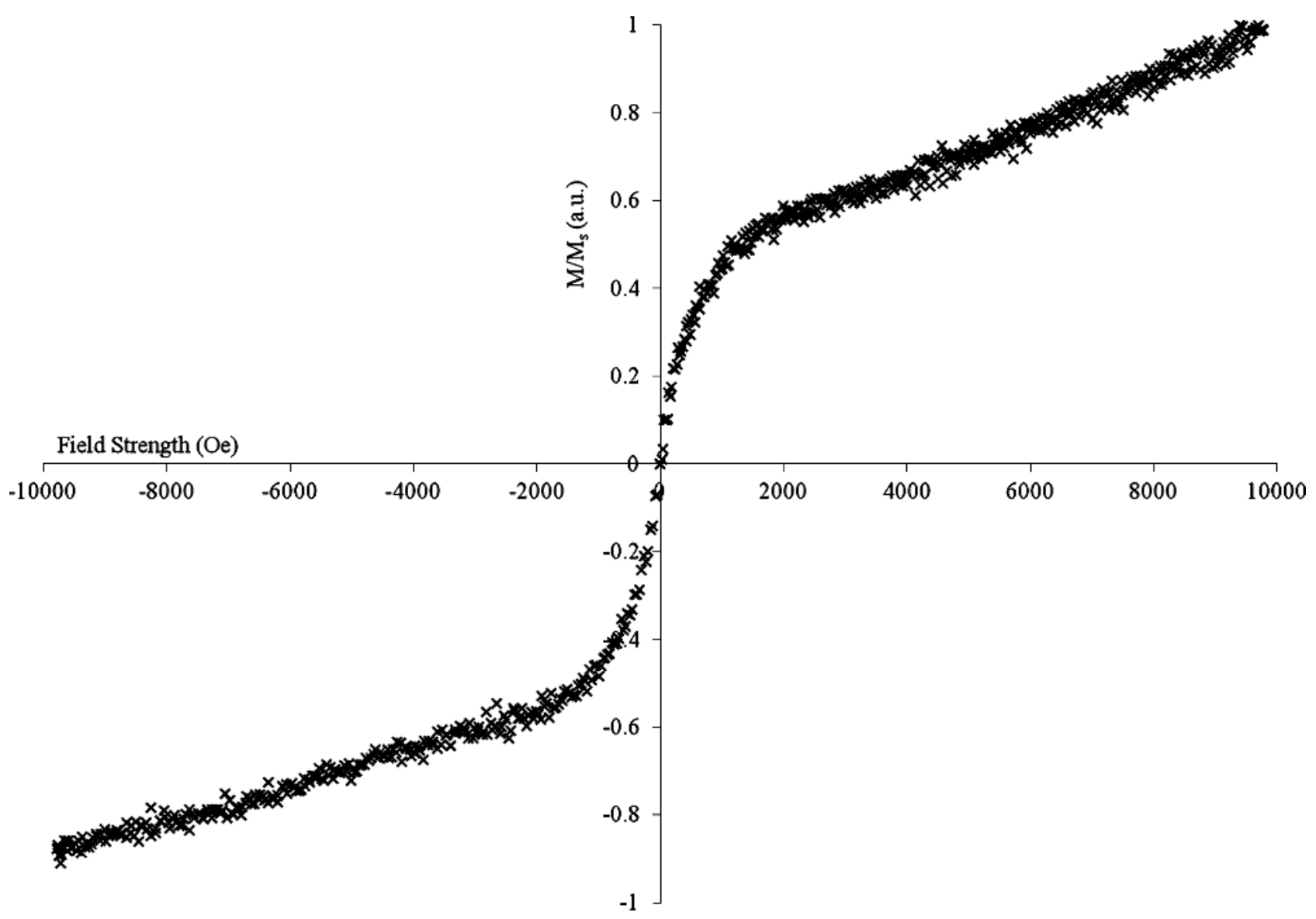

Figure 4. Hysteresis loop of iron oxide nanoparticles. 
oxidizing or reducing reagents. Furthermore, cation doping of the nanoparticles could also be easily achieved within this system, leading to further alteration of the particles magnetic properties.

In summary, iron oxide nanoparticles (IONs) have been synthesised for the first time in commercially available microreactors using a laminar flow technique. The careful control of precipitation using the laminar flow technique gave nanoparticles of similar size and polydispersity to those prepared in homemade continuous flow reactors while avoiding channel blockage; no fouling observed after 40 hours of operation. Furthermore, the phase composition of the nanoparticles has been comprehensively analyzed, and the samples found to contain $71.8 \% \gamma-\mathrm{Fe}_{2} \mathrm{O}_{3}$ and $28.2 \% \mathrm{Fe}_{3} \mathrm{O}_{4}$ by weight.

\section{Experimental Section}

The microreactor was obtained from Chemtrix BV, as part of the Labtrix ${ }^{\circledR}$ Start equipment. The device comprises of one etched layer and one cover plate, the isotropic channels have a depth of $60 \mu \mathrm{m}$ and width of $300 \mu \mathrm{m}$, with a total volume of $10 \mu 1$. Chemyx syringe pumps, also obtained as part of the Labtrix ${ }^{\circledR}$ Start equipment, were used to control the flow rates of the reagents.

As starting materials, $\mathrm{FeCl}_{2} \cdot 4 \mathrm{H}_{2} \mathrm{O}$ (98\%, Sigma-Aldrich), $\mathrm{FeCl}_{3}$ (>97\%, Fischer Scientific), sodium hydroxide (Fischer Scientific), and hydrochloric acid (35\% $\mathrm{HCl}$, Sigma-Aldrich) were used. An iron salts precursor solution (ISPS) was first formed by mixing equal volumes of $0.01 \mathrm{~mol} \mathrm{dm}^{-3}$ iron (II) chloride and $0.02 \mathrm{~mol} \mathrm{dm}^{-3}$ iron (III) chloride in hydrochloric acid $\left(1.1 \mathrm{~mol} \mathrm{dm}^{-3}\right)$. A solution of sodium hydroxide $\left(1.0 \mathrm{~mol} \mathrm{dm}^{-3}\right)$ was used as a base. The solutions were first deoxygenated with nitrogen for 1 hour prior to their use. When synthesizing nanoparticles within the microreactor $1 \mathrm{ml} \mathrm{SGE}$ gas tight syringes (Supelco) and gas impermeable PEEK tubing were used to pump the starting reagents into the reactor simultaneously so as to obtain continuous flow. The precipitate was collected under a nitrogen atmosphere and extracted using magnetic decantation, in which a neodynium bar magnet is used to collect the magnetic particles while the filtrate and any non-magnetic bi-products are discarded.

PXRD patterns were recorded using a Siemens D5000 X-ray Diffractometer, using a $\mathrm{CuK} \alpha$ radiation $(\lambda=1.540598 \AA)$. For the construction of the calibration graph to determine the weight percentage of $\gamma-\mathrm{Fe}_{2} \mathrm{O}_{3}$ within the sample, PXRD patterns of iron (III) oxide nanopowder (Sigma Aldrich, particle size $<50 \mathrm{~nm}$ ) and iron (II,III) oxide powder (Sigma Aldrich) mixed in different ratios were run. The peak intenstities of the (511) and (440) reflections were then deconvoluted into the two peaks for $\gamma-\mathrm{Fe}_{2} \mathrm{O}_{3}$ and $\mathrm{Fe}_{3} \mathrm{O}_{4}$. A calibration graph of the integrated intensity against percentage weight of $\gamma-\mathrm{Fe}_{2} \mathrm{O}_{3}$ was then plotted. The (511) and (440) reflections of the samples prepared within the microreactor were then measured and compared to the calibration graph to determine the weight percentage of $\gamma-\mathrm{Fe}_{2} \mathrm{O}_{3}$ within the sample.

Magnetic measurements were performed using a home made Vibrating Sample Magnetometer (VSM) at room temperature. TEM images were obtained on a JEOL transmission electron microscope operating at $120 \mathrm{kV}$.

\section{References and Notes}

1. Frenz, L.; El Harrak, A.; Pauly, M.; Begin-Colin, S.; Griffiths, A. D.; Baret, J. C. Angew. Chem. Int. Ed. 2008, 47, 6817-6820.

2. Abou Hassan, A.; Sandre, O.; Cabuil, V.; Tabeling, P. Chem. Comm. 2008, 1783-1785.

3. Kumar, K.; Nightingale, A. M.; Krishnadasan, S. H.; Kamaly, N.; Wylenzinska-Arridge, M.; Zeissler, K.; Branford, W. R.; Ware, E.; deMello, A. J.; deMello, J. C. J. Mater. Chem. 2012, 22, 4704-4708.

4. Chin, S. F.; Iyer, K. S.; Raston, C. L.; Saunders, M. Adv. Funct. Mater. 2008, 18, 922-927.

5. Crow, M. in Chemistry World, Royal Society of Chemistry, 2012, 9, 48-51. 6. Zhao, C. H.; He, L.; Qiao, S. Z.; Middelberg, A. P. J. Chem. Eng. Sci. 2011, 66, 1463-1479.

7. Wiles, C.; Watts, P. Chem. Comm. 2011, 47, 6512-6535.

8. Watts, P.; Wiles, C. Chem. Comm. 2007, 443-467.

9. Pumera, M. Chem Comm 2011, 47, 5671-5680.

10. Wagner, J.; Kohler, J. M. Nano Lett. 2005, 5, 685-691.

11. Xue, Z. L.; Terepka, A. D.; Hong, Y. Nano Lett. 2004, 4, 2227-2232.

12. Song, Y. J.; Kumar, C.; Hormes, J. J. Nanosci. Nanotechnol. 2004, 4, $788-793$.

13. Song, Y. J.; Li, R. S.; Sun, Q. Q.; Jin, P. Y. Chem. Eng. J. 2011, 168, 477-484

14. Eun, T. H.; Kim, S. H.; Jeong, W. J.; Jeon, S. J.; Yang, S. M. Chem. Mater. 2009, 21, 201-203.

15. Khan, S. A.; Gunther, A.; Schmidt, M. A.; Jensen, K. F. Langmuir 2004, 20, 8604-8611.

16. Khan, S. A.; Jensen, K. F. Adv. Mater. 2007, 19, 2556-2560.

17. Krishnadasan, S.; Tovilla, J.; Vilar, R.; deMello; deMello, J. C. J. Mater. Chem. 2004, 14, 2655-2660.

18. McAteer, M. A.; Schneider, J. E.; Ali, Z. A.; Warrick, N.; Bursill, C. A.; von zur Muhlen, C.; Greaves, D. R.; Neubauer, S.; Channon, K. M.; Choudhury, R. P. Arterioscle. Thromb. Vas. 2008, 28, 77-83.

19. Janib, S. M.; Moses, A. S.; MacKay, J. A. Adv. Drug Deliver. Rev. 2010, $62,1052-1063$.

20. Pradhan, P.; Giri, J.; Samanta, G.; Sarma, H. D.; Mishra, K. P.; Bellare, J.;

Banerjee, R.; Bahadur, D. J. Biomed. Mater. Res. B 2007, 81B, 12-22.

21. Qiao, R. R.; Yang, C. H.; Gao, M. Y. J. Mater. Chem. 2009, 19, 6274-6293.

22. Jorgensen, J. E.; Mosegaard, L.; Thomsen, L. E.; Jensen, T. R.; Hanson, J. C.

J. Solid State Chem. 2007, 180, 180-185.

23. Greaves, C. J. Solid State Chem. 1983, 49, 325-333.

24. Bastow, T. J.; Trinchi, A; Hill, M. R.; Harris, R.; Muster, T. H. J. Magn. Magn. Mater. 2009, 321, 2677-2681.

25. Cornell, R. M.; Schwertmann, U. The Iron Oxides: Structure, Properties, Reactions, Occurences and Uses., Second edn., Wiley-VCH, 2003.

26. Park, J.; Lee, E.; Hwang, N.-M; Kang, M.; Kim, S. C.; Hwang, Y.; Park, J.-G.; Noh, H.-J.; Kim, J.-Y.; Park, J.-H.; Hyeon, T. Angew. Chem. Int. Ed. 2005, 44, 2873-2877.

27. Kim, W.; Suh, C. Y.; Cho, S. W.; Roh, K. M.; Kwon, H.; Song, K.; Shon, I. J. Talanta 2012, 94, 348-352.

28. Gupta, A. K.; Gupta, M. Biomaterials 2005, 26, 3995-4021.

29. Darezereshki, E. Mater. Lett. 2010, 64, 1471-1472.

30. Salazar, J. S.; Perez, L.; de Abril, O.; Lai, T. P.; Ihiawakrim, D.; Vazquez, M.; Greneche, J. M.; Begin-Colin, S.; Pourroy, G. Chem. Mater. 2011, 23, 1379-1386. 31. Jenkins, R.; Snyder, R. L. Introduction to X-ray Powder Diffractometry, Wiley \& Sons, Inc., 1996.

32. Fleet, M. E. J. Solid State Chem. 1986, 62, 75-82.

33. Feitknecht, W. Rev. Pure Appl. Chem. 1964, 423-440. 